\title{
Case-control study of markers of insulin resistance and endometrial cancer risk
}

\author{
Christine M Friedenreich ${ }^{1,2,3}$, Annie $R$ Langley $^{1}$, Thomas $P$ Speidel ${ }^{1}$, \\ David C W Lau ${ }^{4,5}$, Kerry S Courneya ${ }^{6}$, Ilona Csizmadi, ${ }^{1,2,3}$ \\ Anthony M Magliocco ${ }^{7}$, Yutaka Yasui ${ }^{8}$ and Linda S Cook ${ }^{1,2,9}$
}

\footnotetext{
${ }^{1}$ Division of Cancer Care, Alberta Health Services, Department of Population Health Research, 2210-2nd Street SW, Calgary, Alberta, Canada T2C 3S3

${ }^{2}$ Department of Community Health Sciences, Faculty of Medicine, University of Calgary, 3330 Hospital Drive NW, Calgary, Alberta, Canada T2N 4N2

${ }^{3}$ Department of Oncology, Faculty of Medicine, University of Calgary, 133129 Street NW, Calgary, Alberta, Canada T2N 4N2 Departments of ${ }^{4}$ Medicine and ${ }^{5}$ Biochemistry and Molecular Biology, Faculty of Medicine, University of Calgary, 3330 Hospital Drive NW, Calgary, Alberta, Canada T2N 4N2

${ }^{6}$ Faculty of Physical Education and Recreation, University of Alberta, E488 Van Vliet Centre, Edmonton, Alberta, Canada T6G 2H9

${ }^{7}$ Department of Anatomical Pathology, H. Lee Moffitt Cancer Centre, 12902 Magnolia Drive, Tampa, Florida 33612, USA

${ }^{8}$ School of Public Health, University of Alberta, 11405 - 87 Avenue Edmonton, Alberta, Canada T6G 1C9

${ }^{9}$ Department of Internal Medicine, NM Health Sciences Center, University of New Mexico, MSC 10 5550, 1 University of New Mexico, Albuquerque, New Mexico 87131-0001, USA
}

(Correspondence should be addressed to C M Friedenreich who is now at Department of Population Health Research, Alberta Health Services - Cancer Care, Box ACB, 2210-2nd Street SW, Calgary, Alberta, Canada T2S 3C3;

Email: christine.friedenreich @albertahealthservices.ca)

\begin{abstract}
Markers of insulin resistance such as the adiponectin:leptin ratio $(A: L)$ and the homeostasis model assessment ratio (HOMA-IR) are associated with obesity and hyperinsulinemia, both established risk factors for endometrial cancer, and may therefore be informative regarding endometrial cancer risk. This study investigated the association between endometrial cancer risk and markers of insulin resistance, namely adiponectin, leptin, the A:L ratio, insulin, fasting glucose, and the HOMA-IR. We analyzed data from 541 incident endometrial cancer cases and 961 frequency agematched controls in a population-based case-control study in Alberta, Canada from 2002 to 2006. Participants completed interview-administered questionnaires were assessed for anthropometric measures, and provided 8-h fasting blood samples either pre- or postoperatively. Blood was analyzed for concentrations of leptin, adiponectin, and insulin by immunoassay, and fasting plasma glucose levels were determined by fluorimetric quantitative determination. Compared with the lowest quartile, the highest quartile of insulin and HOMA-IR was associated with $64 \%(95 \%$ confidence intervals $(\mathrm{Cl}): 1.12-2.40)$ and $72 \%(95 \% \mathrm{Cl}: 1.17-2.53)$ increased risks of endometrial cancer, respectively, and the highest quartile of adiponectin was associated with a $45 \%(95 \% \mathrm{Cl}$ : $0.37-0.80$ ) decreased risk after multivariable adjustments. Null associations were observed between fasting glucose, leptin and $A: L$, and endometrial cancer risk. This population-based study provides evidence for a role of insulin resistance in endometrial cancer etiology and may provide one possible pathway whereby obesity increases the risk of this common cancer. Interventions aimed at decreasing both obesity and insulin resistance may decrease endometrial cancer risk.
\end{abstract}

Endocrine-Related Cancer (2012) 19 785-792

\section{Introduction}

Endometrial cancer is the most common gynecological malignancy afflicting Canadian women with an estimated 4700 new cases and 750 associated deaths in 2011 (Canadian Cancer Society 2011). Obesity, the strongest risk factor identified to date (Kaaks et al. 2002), may be associated with endometrial cancer through the release of bioactive substances from adipose tissue (Renehan \& Berster 2008). Adiponectin and leptin, cytokines produced by adipocytes, play an 
important role in the regulation of food intake, energy balance, and glucose and insulin metabolism (Lihn et al. 2005). As markers of insulin resistance, the adiponectin:leptin ratio (A:L) and the homeostasis model assessment ratio (HOMA-IR) may help to explain the association of obesity and endometrial cancer risk.

Leptin and adiponectin function in opposition: while leptin decreases tissue sensitivity to insulin and increases insulin levels (Gnacinska et al. 2009), adiponectin decreases insulin and glucose production (Lihn et al. 2005). Hyperinsulinemia and obesity are therefore associated with high leptin and low adiponectin levels, or a low A:L (Gallagher \& LeRoith 2010). The A:L ratio is considered a practical indicator of insulin resistance in both diabetic (Oda et al. 2008) and nondiabetic (Finucane et al. 2009) individuals, and is strongly associated with the more conventional measure of insulin resistance, HOMA-IR, which is determined from fasting insulin and glucose levels (Finucane et al. 2009). Furthermore, this method may be more sensitive and reliable than HOMA-IR as leptin and adiponectin are more stable in serum than insulin (Finucane et al. 2009). To date, no studies have investigated the relationship between HOMA-IR and endometrial cancer, and very few studies have assessed the influence of other measures of insulin resistance and endometrial cancer risk.

This population-based case-control study of endometrial cancer examined the association of markers of insulin resistance, namely the $A: L$ ratio and HOMA-IR, and endometrial cancer risk. Secondary objectives included estimating the risk of endometrial cancer associated with the levels of insulin, fasting glucose, and leptin and adiponectin.

\section{Materials and methods}

\section{Study population}

From 2002 to 2006, a population-based case-control study of endometrial cancer was conducted in Alberta, Canada, the details of which have been described elsewhere (Friedenreich et al. 2010). Using a rapid case ascertainment method with the Alberta Cancer Registry and pathology reports, 549 incident, histologically confirmed, primary endometrial cancer cases were recruited. Population-based controls $(n=1036)$ were recruited through random digit dialing (Waksberg 1978), and were frequency-matched to cases in 5-year age-groups in a 2:1 ratio. Response rates of 67.9 and $52.2 \%$ were achieved for cases and controls respectively. Participants had no previous cancer history (excluding nonmelanoma skin cancer); in addition, controls had no history of hysterectomy or endometrial ablation. Individuals were excluded from the present analysis if they did not provide blood samples $(n=20$ cases, $n=56$ controls), if interviews were unsatisfactory ( $n=7$ cases, $n=4$ controls), or if they were missing any of the covariate information used in multivariable modeling ( $n=8$ cases, $n=15$ controls). Our final analytic sample consisted of 514 cases and 961 controls. All participants provided informed, written consent, and ethical approval for the study was obtained from the Alberta Cancer Board and the University of Calgary Ethics Review Boards.

\section{Data collection}

Participants completed structured, in-person interviews that collected information on demographic characteristics, endometrial cancer risk factors, lifetime total physical activity levels, smoking history, and hormone use. Cognitive interviewing methods were used to facilitate recall of previous activity patterns and lifestyle behaviors. Anthropometric measures (height, weight, waist, and hip circumferences) were taken in three repeat measurements in a standardized fashion, and mean values of each measure used for analysis.

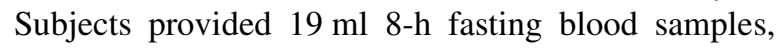
which for cases were collected before surgery whenever possible $(n=235$ presurgical and $n=279$ postsurgical bloods). Blood samples were processed into fractions of serum, plasma, red blood cells, and buffy coat, and aliquoted into cryovials that were frozen at $-86^{\circ} \mathrm{C}$ until analysis. All samples were processed and frozen for storage within 24-h of collection and held in a central biorepository maintained at the Tom Baker Cancer Centre and Holy Cross Centre (Calgary, Canada).

\section{Laboratory assays}

Assays were completed by a sole technician who was blinded to the case-control status of the samples in the laboratory of Dr Lau at the University of Calgary. Assays were run in batches of 72 samples (cases and controls in 1:2 ratios) that corresponded to the sequence of data collection. Four quality assurance specimens were included in each assay: i) a pooled serum sample from women of a similar age from the study participants, ii) one randomly drawn case sample, iii) one randomly drawn control sample, and iv) a pooled sample of the selected case and control samples. Serum concentrations of adiponectin and leptin were measured by ELISA (Alpo Diagnostics, Salem, NH, USA) of insulin by RIA (Linco Research, 
St Charles, MO, USA), and plasma concentrations of glucose by fluorimetric quantitative determination (Bioassay Systems, Hayward, CA, USA). Mean intraand inter-batch coefficients of variation were, respectively, 4.6 and $5.6 \%$ for adiponectin, 4.3 and $7.9 \%$ for leptin, 5.0 and $5.3 \%$ for insulin, and 3.7 and $4.6 \%$ for glucose.

\section{Statistical analysis}

Unconditional logistic regression analyses were conducted to estimate odds ratios (OR) and 95\% confidence intervals (CI) as an estimate for the relative risk (Breslow 1982) for endometrial cancer in relation to insulin, glucose, HOMA-IR, leptin, adiponectin, and the A:L ratio. Several variables were identified a priori as potentially important covariates to adjust for. Variables that displayed univariate associations with case-control status $(P<0.25)$ and which were also assessed for confounding with all significant covariates in the model included: age at reference, parity (nulliparous vs multiparous), menopausal status and hormone use, oral contraceptive, residential status, type II diabetes, hypertension, number of other comorbidities (modeled as a continuous variable with values of 0,1 , or $\geq 2$ for the following conditions: hypertension, thrombosis, pulmonary embolism, myocardial infarction, angina pectoris, stroke, high cholesterol), hours of lifetime total physical activity, weight, height, waist-to-hip ratio at reference, alcohol consumption (ever $>2.0 \mathrm{~g} /$ day), and glycemic load. Other variables that were not considered further for selection (because the univariate association with endometrial cancer was not statistically significant with $P>0.25$ ) included age at menarche, age at menopause (for postmenopausal participants), total hours of sedentary activity, total MET-h of total physical activity, smoking status, and marital status. In the multivariable regression models, confounding variables that altered main effect estimates by $\geq 15 \%$ (Greenland 1989) or variables that were significant at the 0.05 level and which added prediction to the final models were adjusted for, except for age and weight which were forced into all models. Two sets of multivariable models were estimated, the first were adjusted for these covariates and the second set also included mutual adjustment for each of the other insulin-related biomarkers being assessed here.

All quartiles were based on the distribution of the controls. Locally weighted scatterplot smoothing (LOWESS) on all continuous covariates was used as a guide for linearity (Cleveland 1979). Restricted cubic splines were used to model nonlinear covariates followed by a joint test to confirm the need for nonlinear terms (Harrell 2001). Collinearity for groups of similar variables was assessed via variance inflation factor and tolerance. Redundancy analyses were used to suggest which variables among a group of similar variables can be predicted from the remaining variables. The bootstrap method was used to select a reduced model (Efron \& Tibshirani 1994). For continuous variables we used the interquartile range (75th quartile-25th quartile) as a meaningful increment change for the biomarkers. Regression diagnostics and influence statistics were completed for final regression models to assess adherence to regression assumptions, and the Hosmer-Lemeshow goodness-of-fit test to assess model fit (Hosmer 2000). All statistical analyses were completed using the $\mathrm{R}$ Statistical Software Package version 2.15 ( $\mathrm{R}$ Development Core Team) and Stata version 12 (StataCorp., College Station, TX, USA).

\section{Results}

Cases were generally heavier, had larger waist and hip circumferences, and had a higher prevalence of comorbidities compared with controls. Cases and controls were comparable on other characteristics such as age, height, menopausal status, hormone use, and residential status (Table 1).

Overall, cases had higher levels of leptin, insulin, and glucose; lower levels of adiponectin; and higher measures of insulin resistance according to both the A:L ratio and the HOMA-IR (Table 1). In ageadjusted analyses, increased levels of insulin, glucose, leptin, and HOMA-IR were associated with increased risks of endometrial cancer, and increase in adiponectin levels, and the A:L ratio was associated with a reduction in risk (Table 2). Increasing categorical levels of biomarkers was associated with increased endometrial cancer risk $(P<0.05$ for all; Table 2).

Most associations of biomarkers and endometrial cancer risk remained with multivariable adjustments, except for leptin, the A:L ratio, and glucose, for which multivariable-adjusted ORs were not statistically significant (Table 3). Compared with the lowest quartile, the highest quartile of insulin and HOMA-IR was associated with 64\% (95\% CI: 1.12-2.40) and 72\% (95\% CI: 1.17-2.53) increased risks of endometrial cancer, respectively, and the highest quartile of adiponectin was associated with a $45 \%$ (95\% CI: $0.37-0.80)$ decreased risks of endometrial cancer. 
Table 1 Distributions of selected characteristics among cases and controls $(n=1476)$

\begin{tabular}{|c|c|c|}
\hline Risk factor median (25th, 75th percentiles) or $\boldsymbol{n}(\%)$ & Cases $(n=514)$ & Controls $(n=962)$ \\
\hline Age (years) & $59(53,65)$ & $59(52,66)$ \\
\hline Hip circumference $(\mathrm{cm})$ & $110.9(102.6,123.5)$ & $104.8(99,112.5)$ \\
\hline Waist circumference $(\mathrm{cm})$ & $95.5(84,108.6)$ & $84.5(76.5,95.5)$ \\
\hline Waist-to-hip ratio (0.1 increments) & $8.5(7.9,8.9)$ & $8.1(7.6,8.6)$ \\
\hline Weight $(\mathrm{kg})$ & $81.1(68.6,98)$ & $71.5(63.1,81.6)$ \\
\hline Height $(\mathrm{cm})$ & $162.2(157.5,166.4)$ & $161.8(157.8,166.3)$ \\
\hline BMI $\left(\mathrm{kg} / \mathrm{m}^{2}\right)$ & $31.0(26.4,36.8)$ & $27.2(24.1,30.9)$ \\
\hline Nulliparous (vs multiparous) & $92(17.9 \%)$ & $89(9.3 \%)$ \\
\hline \multicolumn{3}{|l|}{ HRT and menopause } \\
\hline Peri and post, no HRT (referent) & $281(54.7 \%)$ & $480(49.9 \%)$ \\
\hline Peri and post, estrogen only & $20(3.9 \%)$ & $25(2.6 \%)$ \\
\hline Peri and post, estrogen and progestin & $132(25.7 \%)$ & $322(33.5 \%)$ \\
\hline Peri and post, other hormones & $27(5.3 \%)$ & $26(2.7 \%)$ \\
\hline Premenopausal & $54(10.5 \%)$ & $109(11.3 \%)$ \\
\hline Ever $>2.5 \mathrm{~g} /$ day of ethanol & $137(27.3 \%)$ & $395(41.2 \%)$ \\
\hline Rural residential area (vs urban) & $165(32.1 \%)$ & $334(34.7 \%)$ \\
\hline Type II diabetes & $62(12.1 \%)$ & $51(5.3 \%)$ \\
\hline Medicated & $43(8.4 \%)$ & $40(4.2 \%)$ \\
\hline Nonmedicated & $19(3.7 \%)$ & $11(1.1 \%)$ \\
\hline Ever hypertension & $161(31.3 \%)$ & $171(17.8 \%)$ \\
\hline \multicolumn{3}{|l|}{ Number of other comorbidities ${ }^{a}$} \\
\hline 0 & $304(59.1 \%)$ & $652(67.8 \%)$ \\
\hline 1 & $179(34.8 \%)$ & $255(26.5 \%)$ \\
\hline$\geq 2$ & $31(6.0 \%)$ & $55(5.7 \%)$ \\
\hline Insulin (mIU/l) & $6.6(4.2,10.9)$ & $4.8(3.3,7.2)$ \\
\hline Glucose & $113.9(90.7,144.6)$ & $103.7(84.7,134.9)$ \\
\hline HOMA-IR & $1.8(1.1,3.2)$ & $1.2(0.8,2.0)$ \\
\hline Adiponectin $(\mu \mathrm{g} / \mathrm{ml})$ & $11.6(7.7,17.3)$ & $14.6(10.0,21.5)$ \\
\hline Leptin $(\mathrm{mg} / \mathrm{ml})$ & $44.2(23.5,72.4)$ & $28.2(18.1,47.5)$ \\
\hline Adiponectin:leptin ratio & $3.6(1.6,7.6)$ & $1.9(1.1,4.1)$ \\
\hline
\end{tabular}

${ }^{a}$ Other comorbidities include thrombosis, pulmonary embolism, myocardial infarction, angina pectoris, stroke, and high cholesterol.

\section{Discussion}

This large, population-based case-control study of endometrial cancer in Alberta, Canada observed increased risks for endometrial cancer with increased levels of insulin and HOMA-IR and decreased levels of adiponectin, using both continuous and categorical classification of variables. Effect estimates were of moderate size, ranging from 45 to $72 \%$.

Few studies have investigated the associations between insulin resistance and endometrial cancer risk. Retrospective case-control studies have identified relationships between endometrial cancer risk and the levels of leptin (Ashizawa et al. 2010), adiponectin (Petridou et al. 2003, Dal Maso et al. 2004), and the A:L ratio (Ashizawa et al. 2010), but not insulin levels (Weiderpass et al. 2003). Two (Petridou et al. 2003, Dal Maso et al. 2004) of four studies (Petridou et al. 2003, Dal Maso et al. 2004, Ashizawa et al. 2010, Lasalandra et al. 2010) that measured adiponectin found evidence for an association with endometrial cancer risk. One of the negative studies (Lasalandra et al. 2010) used hospital-based controls with benign disease and provided no multivariable adjusted risk estimates, and so the results of this study may be confounded. Only one study has investigated the association between endometrial cancer and leptin and the A:L ratio (defined here as the L:A ratio); in this retrospective analysis, leptin levels and the L:A ratio were significantly higher in endometrial cancer cases compared with controls (Ashizawa et al. 2010). Prospective, nested case-control studies within the European Investigation into Cancer (EPIC; Cust et al. 2007), the Nurses Health Study (NHS; Soliman et al. 2011), and the Women's Health Initiative (WHI; Gunter et al. 2008) cohorts that measured the levels of biomarkers from prediagnostically collected blood samples provide some support for the relationship of insulin resistance and endometrial cancer. Consistent with our results, the EPIC and WHI studies found an inverse association between endometrial cancer risk and adiponectin (Cust et al. 2007) and insulin levels (Gunter et al. 2008) respectively. However, no relationship was observed for adiponectin in the NHS (Soliman et al. 2011). To our knowledge, no previous 
Table 2 Age-adjusted odds ratios (OR) for selected characteristics and endometrial cancer risk $(n=1476)$

\begin{tabular}{|c|c|c|}
\hline Risk factor & OR & $95 \% \mathrm{Cl}$ \\
\hline Age (years) & NA & NA \\
\hline Hip circumference $(\mathrm{cm})$ & 1.04 & $1.03,1.05$ \\
\hline Waist circumference $(\mathrm{cm})$ & 1.04 & $1.03,1.05$ \\
\hline Waist-to-hip ratio (0.1 increments) & 1.62 & $1.41,1.86$ \\
\hline Weight $(\mathrm{kg})$ & 1.03 & $1.03,1.04$ \\
\hline Height (cm) & 1.00 & $0.98,1.01$ \\
\hline BMI $\left(\mathrm{kg} / \mathrm{m}^{2}\right)$ & 1.10 & $1.08,1.12$ \\
\hline Nulliparous (vs multiparous) & 2.19 & $1.60,3.00$ \\
\hline \multicolumn{3}{|l|}{ HRT and menopause } \\
\hline Peri and post, no HRT (referent) & 1.00 & - \\
\hline Peri and post, estrogen only & 1.30 & $0.71,2.40$ \\
\hline Peri and post, estrogen and progestin & 0.68 & $0.53,0.88$ \\
\hline Peri and post, other hormones & 1.69 & $0.97,2.94$ \\
\hline Premenopausal & 0.92 & $0.60,1.40$ \\
\hline Ever $>2.0 \mathrm{~g}$ ethanol $/$ day & 0.53 & $0.42,0.68$ \\
\hline Rural residential area (vs urban) & 0.88 & $0.70,1.11$ \\
\hline Type II diabetes & 2.38 & $1.62,3.51$ \\
\hline Ever hypertension & 2.22 & $1.72,2.88$ \\
\hline Number of other comorbidities & 1.29 & $1.08,1.55$ \\
\hline Insulin (continuous 4.7 mIU/I, IQR) & 1.66 & $1.48,1.86$ \\
\hline \multicolumn{3}{|l|}{ Insulin (quartiles) } \\
\hline$\leq 3.3$ (referent) & 1.00 & - \\
\hline$>3.3$ to $\leq 4.8$ & 1.08 & $0.75,1.55$ \\
\hline$>4.8$ to $\leq 7.2$ & 1.63 & $1.16,2.28$ \\
\hline$>7.2$ & 3.18 & $2.32,4.36$ \\
\hline$P$-trend & & $<0.0001$ \\
\hline $\begin{array}{l}\text { Glucose (continuous } 52.4 \text { mg/dl, } \\
\text { IQR) }\end{array}$ & 1.26 & $1.11,1.43$ \\
\hline \multicolumn{3}{|l|}{ HOMA-IR (quartiles) } \\
\hline$\leq 0.80$ (referent) & 1.00 & - \\
\hline$>0.80$ to $\leq 1.20$ & 1.25 & $0.87,1.80$ \\
\hline$>1.20$ to $\leq 2.00$ & 1.78 & $1.26,2.51$ \\
\hline$>2.00$ & 3.43 & $2.48,4.73$ \\
\hline$P$-trend & & $<0.0001$ \\
\hline Adiponectin (continuous 10.7 g/ml, IQR) & 0.58 & $0.50,0.68$ \\
\hline \multicolumn{3}{|c|}{ Adiponectin (quartiles) } \\
\hline$\leq 10.0$ (referent) & 1.00 & - \\
\hline$>10.0$ to $\leq 14.6$ & 0.58 & $0.43,0.77$ \\
\hline$>14.6$ to $\leq 21.5$ & 0.49 & $0.36,0.66$ \\
\hline$>21.5$ & 0.32 & $0.23,0.45$ \\
\hline$P$-trend & & $<0.0001$ \\
\hline Leptin (continuous 37.1 mg/ml, IQR) & 1.65 & $1.46,1.86$ \\
\hline \multicolumn{3}{|l|}{ Leptin (quartiles) } \\
\hline$\leq 18.1$ (referent) & 1.00 & - \\
\hline$>18.1$ to $\leq 28.2$ & 1.36 & $0.96,1.92$ \\
\hline$>28.2$ to $\leq 47.3$ & 1.38 & $0.97,1.96$ \\
\hline$>47.3$ & 3.18 & $2.32,4.37$ \\
\hline$P$-trend & & $<0.0001$ \\
\hline Adiponectin:leptin ratio & 0.79 & $0.71,0.89$ \\
\hline
\end{tabular}

Quartiles based on the distribution of the control.

study has investigated the relationship between endometrial cancer and the HOMA-IR.

Besides endometrial cancer, the levels of leptin and adiponectin have been associated with the risk of other cancer types including breast, colon, and prostate
(Tworoger et al. 2007, Guadagni et al. 2009, Wu et al. 2009, Li et al. 2010), and there is substantial evidence that links various measures of insulin resistance with the development of cancer and precancerous conditions (Godsland 2010).

It is biologically plausible that insulin resistance is associated with endometrial cancer risk. Obesity, the most well-established endometrial cancer risk factor (Kaaks et al. 2002), may be associated with endometrial cancer through the release of bioactive substances from adipose tissue (Renehan \& Berster 2008), including adiponectin and leptin. These adipokines help to regulate the levels and sensitivity of insulin, which is hypothesized to stimulate the growth of endometrial stromal cells upon binding to insulin receptors on endometrial cell membranes (Nagamani \& Stuart 1998). As markers of insulin resistance, the A:L ratio and HOMA-IR may therefore help to explain the association of obesity and endometrial cancer risk. Another possible explanation for these findings is that the endometrial cancer may have resulted in an over-expression of insulin receptors and insulin-like growth factor type I receptors and the expression of hybrid isoforms of both which have been observed with endometrial carcinoma (Belfiorni \& Malaguarnera 2011).

Several study limitations must be considered in light of our findings. As with previous retrospective investigations, in our study it is possible that measures of insulin resistance in cases were influenced by the presence of cancer or cancer treatment, as a proportion of cases provided postoperative blood samples. As cancer surgery elicits a peri-operative metabolic response (Kehlet 2000), it is possible that the levels of markers were altered among some cases. However, postoperative blood samples were collected after a minimum of 28 days postsurgery (for a median of 5 months), by which time metabolic function is likely to have been restored. Furthermore, our results are in line with those produced from prospective nested casecontrol studies which collected pre-diagnostic blood samples (Cust et al. 2007, Gunter et al. 2008). Our research is also limited by the collection of only one blood sample and the potential misclassification of biomarker levels based on a single measure. However, research shows that the levels of adipokines in blood are relatively stable over a period of up to 4 years (Chu et al. 2001, Pischon et al. 2003) and HOMA-IR is considered a valid and reproducible measure of insulin resistance (Sarafidis et al. 2007), although it is recognized that the gold standard approach for assessing insulin sensitivity is the euglycemic insulin clamp. Given the constraints of this population-based, 
Table 3 Multivariable-adjusted odds ratios (OR) estimates and associated 95\% confidence intervals (Cl) for insulin resistance biomarkers and endometrial cancer risk $(n=1476)$

\begin{tabular}{|c|c|c|c|c|c|c|}
\hline Biomarker & Cases $(n)$ & Controls $(n)$ & OR $^{\mathrm{a}}$ & $95 \% \mathrm{Cl}$ & $\mathbf{O R}^{\mathrm{b}}$ & $95 \% \mathrm{Cl}$ \\
\hline Insulin (continuous 4.7 mIU/l, IQR) & & & 1.33 & $1.17,1.51$ & 1.27 & $1.12,1.45$ \\
\hline \multicolumn{7}{|l|}{ Insulin (quartiles) } \\
\hline$\leq 3.3$ (referent) & 75 & 242 & 1.00 & - & 1.00 & - \\
\hline$>3.3$ to $\leq 4.8$ & 80 & 239 & 0.90 & $0.61,1.31$ & 0.89 & $0.61,1.31$ \\
\hline$>4.8$ to $\leq 7.2$ & 122 & 241 & 1.24 & $0.86,1.78$ & 1.23 & $0.85,1.78$ \\
\hline$>7.2$ & 237 & 240 & 1.76 & $1.20,2.55$ & 1.64 & $1.12,2.40$ \\
\hline$P$-trend & & & & $<0.001$ & & 0.023 \\
\hline Glucose (continuous $52.4 \mathrm{mg} / \mathrm{dl}, \mathrm{IQR})^{\mathrm{c}}$ & & & 1.15 & $1.00,1.31$ & 1.10 & $0.96,1.26$ \\
\hline \multicolumn{7}{|l|}{ HOMA-IR (quartiles) } \\
\hline$\leq 0.80$ (referent) & 69 & 241 & 1.00 & - & 1.00 & - \\
\hline$>0.80$ to $\leq 1.20$ & 86 & 240 & 1.11 & $0.76,1.62$ & 1.08 & $0.73,1.57$ \\
\hline$>1.20$ to $\leq 2.00$ & 123 & 241 & 1.36 & $0.94,1.97$ & 1.29 & $0.89,1.88$ \\
\hline$>2.00$ & 236 & 240 & 2.01 & $1.40,2.90$ & 1.72 & $1.17,2.53$ \\
\hline$P$-trend & & & & $<0.001$ & & 0.007 \\
\hline Adiponectin (continuous $10.7 \mu \mathrm{g} / \mathrm{ml}, \mathrm{IQR}$ ) & & & 0.71 & $0.60,0.83$ & 0.76 & $0.64,0.89$ \\
\hline \multicolumn{7}{|l|}{ Adiponectin (quartiles) } \\
\hline$\leq 10.0$ (referent) & 208 & 237 & 1.00 & - & 1.00 & - \\
\hline$>10.0$ to $\leq 14.6$ & 127 & 244 & 0.65 & $0.48,0.89$ & 0.69 & $0.50,0.94$ \\
\hline$>14.6$ to $\leq 21.5$ & 106 & 239 & 0.68 & $0.49,0.94$ & 0.75 & $0.54,1.05$ \\
\hline$>21.5$ & 73 & 241 & 0.47 & $0.33,0.69$ & 0.55 & $0.37,0.80$ \\
\hline$P$-trend & & & & $<0.001$ & & 0.004 \\
\hline Leptin (continuous 37.1 mg/ml, IQR) & & & 1.10 & $0.92,1.30$ & 1.00 & $0.83,1.20$ \\
\hline \multicolumn{7}{|l|}{ Leptin (quartiles) } \\
\hline$\leq 18.1$ (referent) & 74 & 240 & 1.00 & - & 1.00 & - \\
\hline$>18.1$ to $\leq 28.2$ & 101 & 241 & 1.17 & $0.81,1.70$ & 1.08 & $0.74,1.58$ \\
\hline$>28.2$ to $\leq 47.3$ & 102 & 239 & 0.96 & $0.65,1.43$ & 0.83 & $0.55,11.24$ \\
\hline$>47.3$ & 237 & 241 & 1.40 & $0.92,2.13$ & 1.14 & $0.73,1.77$ \\
\hline$P$-trend & & & & 0.201 & & 0.795 \\
\hline Adiponectin:leptin ratio & & & 0.95 & $0.87,1.02$ & 0.97 & $0.89,1.03$ \\
\hline
\end{tabular}

${ }^{a}$ Adjusted for age at reference, nulliparous (vs multiparous), HRT, menopausal hormone use, hypertension, weight at reference date, and waist-to-hip ratio.

${ }^{\mathrm{b}}$ In addition to covariates, mutually adjusted for each of the other biomarkers (glucose, leptin, insulin, and adiponectin).

${ }^{\mathrm{c}}$ Additionally adjusted for alcohol intake ( $>2.5 \mathrm{~g}$ ethanol/day).

province-wide study, we were unable to perform that assessment of insulin sensitivity and chose, instead, to use HOMA-IR as a proxy measure. Any remaining random misclassification of marker levels among cases and controls would be likely to reduce any differences between the groups and therefore attenuate estimated risks. Given that our study sample included women with diabetes, some of whom were taking diabetes medication, we conducted a sensitivity analysis to assess how our results changed with the exclusion of these women. Negligible changes in ORs were observed when diabetic women were excluded from the analyses. A final limitation to consider is the low response rate, particularly among cases; however, this is unlikely to have introduced bias into our study as participation is unlikely to have been related to exposure measures. Furthermore, cases were similar to controls on many characteristics including residential status (data not shown).
Despite these limitations, our study has several strengths. Our large sample size allowed us to investigate the relation between insulin resistance and endometrial cancer with high precision, and our population-based control sample likely provides adequate representation of the same study base from which cases were accrued. Furthermore, this casecontrol study used comprehensive interviews with study subjects that assessed a large range of important lifestyle and health-related covariates such as hypertension; type II diabetes; history of several other comorbidities including angina pectoris, stroke, thrombosis, hypercholesterolemia, a full dietary history, pack-years of smoking, and the levels of recreational; occupational; and household physical activity.

In conclusion, this population-based study has provided new evidence for a role of insulin resistance in endometrial cancer etiology that may explain one possible pathway, whereby obesity increases the risk of 
this common cancer. Future observational studies, with preferably preoperative blood collection, are needed in this novel area of research, particularly to validate our original finding of an association between HOMA-IR and endometrial cancer risk. Interventions aimed at decreasing both obesity and insulin resistance may decrease endometrial cancer risk.

\section{Declaration of interest}

The authors declare that there is no conflict of interest that could be perceived as prejudicing the impartiality of the research reported.

\section{Funding}

This project was funded by grants from the National Cancer Institute of Canada with funds from the Canadian Cancer Society. C M Friedenreich received career awards from the Canadian Institutes of Health Research and the Alberta Heritage Foundation for Medical Research (AHFMR). L S Cook, K S Courneya, and Y Yasui hold Canada Research Chairs and L S Cook and Y Yasui also received career award funding from AHFMR.

\section{Author contribution statement}

Study coordination was done by Rita Biel, Lisa Strosher, Pam Round, and Aleata Rhyorchuk. Laboratory assays were conducted by Angela Dang-Krawetz. Colleen Lachance, Maryann Lester, Lisa Miller, Catherine Munro, and Polly Pratt recruited controls. Participant interviews were conducted by Tamara Bellmont, Kay Christie, Pearl Cooke, Linda Davison, Carolyn Henderson, Tacey Lawrence, Rosalie Merkosky, Jodi Parrotta, Brenda Platzer, Cyndi Rasa, Nicole Slot, Keely Winnitoy, and Carol-Anne Zawalykut. Quality control of interviews was performed by Jodi Parrotta. Carla Quesnel assisted with administrative tasks and Holly Wilson identified cases from Calgary Laboratory Service pathology reports. Farit Vakhetov performed data management.

\section{References}

Ashizawa N, Yahata T, Quan J, Adachi S, Yoshihara K \& Tanaka K 2010 Serum leptin-adiponectin ratio and endometrial cancer risk in postmenopausal female subjects. Gynecologic Oncology 119 65-69. (doi:10.1016/j.ygyno.2010.07.007)

Belfiorni A \& Malaguarnera R 2011 Insulin receptor and cancer. Endocrine-Related Cancer 18 R125-R147. (doi:10.1530/ERC-11-0074)

Breslow N 1982 Design and analysis of case-control studies. Annual Review of Public Health 3 29-54. (doi:10.1146/ annurev.pu.03.050182.000333)

Chu NF, Spiegelman D, Hotamisligil GS, Rifai N, Stampfer M \& Rimm EB 2001 Plasma insulin, leptin, and soluble TNF receptors levels in relation to obesity-related atherogenic and thrombogenic cardiovascular disease risk factors among men. Atherosclerosis 157 495-503. (doi:10.1016/ S0021-9150(00)00755-3)

Cleveland WS 1979 Robust locally weighted regression and smoothing scatterplots. Journal of the American Statistical Association 74 829-836. (doi:10.1080/ 01621459.1979.10481038)

Cust AE, Kaaks R, Friedenreich C, Bonnet F, Laville M, Lukanova A, Rinaldi S, Dossus L, Slimani N, Lundin E et al. 2007 Plasma adiponectin levels and endometrial cancer risk in pre- and postmenopausal women. Journal of Clinical Endocrinology and Metabolism 92 255-263. (doi:10.1210/jc.2006-1371)

Dal Maso L, Augustin LS, Karalis A, Talamini R, Franceschi S, Trichopoulos D, Mantzoros CS \& La Vecchia C 2004 Circulating adiponectin and endometrial cancer risk. Journal of Clinical Endocrinology and Metabolism 89 1160-1163. (doi:10.1210/jc.2003-031716)

Efron B \& Tibshirani R 1994 An Introduction to the Bootstrap. New York: Chapman \& Hall/CRC.

Finucane FM, Luan J, Wareham NJ, Sharp SJ, O'Rahilly S, Balkau B, Flyvbjerg A, Walker M, Hojlund K, Nolan JJ et al. 2009 Correlation of the leptin:adiponectin ratio with measures of insulin resistance in non-diabetic individuals. Diabetologia 52 2345-2349. (doi:10.1007/ s00125-009-1508-3)

Friedenreich CM, Cook LS, Magliocco AM, Duggan MA \& Courneya KS 2010 Case-control study of lifetime total physical activity and endometrial cancer risk. Cancer Causes \& Control 21 1105-1116. (doi:10.1007/s10552010-9538-1)

Gallagher EJ \& LeRoith D 2010 Insulin, insulin resistance, obesity, and cancer. Current Diabetes Reports 10 93-100. (doi:10.1007/s11892-010-0101-y)

Gnacińska M, Małgorzewicz S, Stojek M, ŁysiakSzydłowska W \& Sworczak K 2009 Role of adipokines in complications related to obesity: a review. Advances in Medical Sciences 54 150-157. (doi:10.2478/v10039-0090035-2)

Godsland IF 2010 Insulin resistance and hyperinsulinaemia in the development and progression of cancer. Clinical Science 118 315-332. (doi:10.1042/CS20090399)

Greenland S 1989 Modeling and variable selection in epidemiologic analysis. American Journal of Public Health 79 340-349. (doi:10.2105/AJPH.79.3.340)

Guadagni F, Roselli M, Martini F, Spila A, Riondino S, D’Alessandro R, Del Monte G, Formica V, Laudisi A, Portarena I et al. 2009 Prognostic significance of serum adipokine levels in colorectal cancer patients. Anticancer Research 29 3321-3327.

Gunter MJ, Hoover DR, Yu H, Wassertheil-Smoller S, Manson JE, Li J, Harris TG, Rohan TE, Xue X, Ho GY et al. 2008 A prospective evaluation of insulin and insulin-like growth factor-I as risk factors for endometrial cancer. Cancer Epidemiology, Biomarkers \& Prevention 17 921-929. (doi:10.1158/1055-9965.EPI-07-2686) 
Harrell FE 2001 Regression Modeling Strategies: with Applications to Linear Models, Logistic Regression, and Survival Analysis. New York: Springer.

Hosmer DWLS 2000 Applied Logistic Regression. New York: Wiley.

Kaaks R, Lukanova A \& Kurzer MS 2002 Obesity, endogenous hormones, and endometrial cancer risk: a synthetic review. Cancer Epidemiology, Biomarkers \& Prevention 11 1531-1543.

Kehlet H 2000 Manipulation of the metabolic response in clinical practice. World Journal of Surgery 24 690-695. (doi:10.1007/s002689910111)

Lasalandra C, Coviello M, Falco G, Divella R, Trojano G, Laterza AM, Quero C, Pepe V, Zito FA \& Quaranta M 2010 Serum vascular endothelial growth factor and adiponectin levels in patients with benign and malignant gynecological diseases. International Journal of Gynecological Cancer 20 507-512. (doi:10.1111/ IGC.0b013e3181c54fc5)

Li H, Stampfer MJ, Mucci L, Rifai N, Qiu W, Kurth T \& Ma J 2010 A 25-year prospective study of plasma adiponectin and leptin concentrations and prostate cancer risk and survival. Clinical Chemistry 56 34-43. (doi:10.1373/ clinchem.2009.133272)

Lihn AS, Pedersen SB \& Richelsen B 2005 Adiponectin: action, regulation and association to insulin sensitivity. Obesity Reviews 6 13-21. (doi:10.1111/j.1467-789X. 2005.00159.x)

Nagamani M \& Stuart CA 1998 Specific binding and growth-promoting activity of insulin in endometrial cancer cells in culture. American Journal of Obstetrics and Gynecology 179 6-12. (doi:10.1016/ S0002-9378(98)70244-3)

Oda N, Imamura S, Fujita T, Uchida Y, Inagaki K, Kakizawa H, Hayakawa N, Suzuki A, Takeda J, Horikawa Y et al. 2008 The ratio of leptin to adiponectin can be used as an index of insulin resistance. Metabolism 57 268-273. (doi:10.1016/ j.metabol.2007.09.011)

Petridou E, Mantzoros C, Dessypris N, Koukoulomatis P, Addy C, Voulgaris Z, Chrousos G \& Trichopoulos D 2003 Plasma adiponectin concentrations in relation to endometrial cancer: a case-control study in Greece. Journal of Clinical Endocrinology and Metabolism 88 993-997. (doi:10.1210/jc.2002-021209)
Pischon T, Hotamisligil GS \& Rimm EB 2003 Adiponectin: stability in plasma over $36 \mathrm{~h}$ and within-person variation over 1 year. Clinical Chemistry 49 650-652. (doi:10.1373/49.4.650)

Renehan AG \& Berster JM 2008 Insulin and Cancer: Report of the Proceedings of the First International Workshop, October 27-28, 2007, Dusseldorf, Germany. Pediatric Endocrinology Reviews 5 810-816.

Sarafidis PA, Lasaridis AN, Nilsson PM, Pikilidou MI, Stafilas PC, Kanaki A, Kazakos K, Yovos J \& Bakris GL 2007 Validity and reproducibility of HOMA-IR, 1/HOMA-IR, QUICKI and McAuley's indices in patients with hypertension and type II diabetes. Journal of Human Hypertension 21 709-716. (doi:10.1038/sj.jhh. 1002201)

Soliman PT, Cui X, Zhang Q, Hankinson SE \& Lu KH 2011 Circulating adiponectin levels and risk of endometrial cancer: the prospective Nurses' Health Study. American Journal of Obstetrics and Gynecology 167 e161-e165. (doi:10.1016/j.ajog.2010.08.045)

Tworoger SS, Eliassen AH, Kelesidis T, Colditz GA, Willett WC, Mantzoros CS \& Hankinson SE 2007 Plasma adiponectin concentrations and risk of incident breast cancer. Journal of Clinical Endocrinology and Metabolism 92 1510-1516. (doi:10.1210/jc.2006-1975)

Waksberg J 1978 Sampling methods for random digit dialing. Journal of the American Statistical Society 73 40-46.

Weiderpass E, Brismar K, Bellocco R, Vainio H \& Kaaks R 2003 Serum levels of insulin-like growth factor-I, IGF-binding protein 1 and 3, and insulin and endometrial cancer risk. British Journal of Cancer 89 1697-1704. (doi:10.1038/sj.bjc.6601312)

Wu MH, Chou YC, Chou WY, Hsu GC, Chu CH, Yu CP, Yu JC \& Sun CA 2009 Circulating levels of leptin, adiposity and breast cancer risk. British Journal of Cancer 100 578-582. (doi:10.1038/sj.bjc.6604913)

\author{
Received in final form 13 September 2012 \\ Accepted 1 October 2012 \\ Made available online as an Accepted Preprint \\ 2 October 2012
}

